\title{
Single dose pharmacokinetics of the novel transdermal donepezil patch in healthy volunteers
}

This article was published in the following Dove Press journal:

Drug Design, Development and Therapy

10 March 2015

Number of times this article has been viewed

\author{
Yo Han Kim' \\ Hee Youn Choi' \\ Hyeong-Seok Lim' \\ Shi Hyang Lee' \\ Hae Sun Jeon' \\ Donghyun Hong ${ }^{2}$ \\ Seong Su Kim² \\ Young Kweon $\mathrm{Choi}^{2}$ \\ Kyun-Seop Bae' \\ 'Department of Clinical Pharmacology \\ and Therapeutics, College of Medicine, \\ University of Ulsan, Asan Medical \\ Center, Seoul, Republic of Korea; \\ ${ }_{2}^{2}$ Cure Pharmaceutical Incorporated, \\ Anseong, Gyeonggi-do, Republic \\ of Korea
}

\begin{abstract}
Background: Donepezil is an acetylcholinesterase inhibitor indicated for Alzheimer's disease. The aim of this randomized, single-blind, placebo-controlled, single-dose, dose-escalation study was to investigate the safety, tolerability, and pharmacokinetics of the donepezil patch in healthy male subjects.
\end{abstract}

Methods: Each healthy male subject received a single transdermal donepezil patch (72 hours patch-on periods) of $43.75 \mathrm{mg} / 12.5 \mathrm{~cm}^{2}, 87.5 \mathrm{mg} / 25 \mathrm{~cm}^{2}$, or $175 \mathrm{mg} / 50 \mathrm{~cm}^{2}$. Serial blood samples were collected up to 312 hours after patch application. The plasma concentrations of donepezil were determined by using a validated liquid chromatography-tandem mass spectrometry method. Pharmacokinetic parameters were obtained by noncompartmental analysis. Tolerability of the patches and performance of the patches (adhesion, skin irritation, residual donepezil content in the patch) were assessed throughout the study.

Results: The study was completed by 36 healthy subjects. After patch application, the maximal plasma donepezil concentration $\left(\mathrm{C}_{\max }\right)$ and the area under the curve (AUC) increased in a doseproportional manner. Median time to $\mathrm{C}_{\max }$ was $\sim 74-76$ hours ( $\sim 2-4$ hours after patch removal), and mean $\mathrm{t}_{1 / 2 \beta}$ was $\sim 63.77-93.07$ hours. The average donepezil residue in the patch after 72 hours was $\sim 73.9 \%-86.7 \%$ of the loading dose. There were neither serious adverse events nor adverse events that lead to discontinuation. Skin adhesion of the patch was good in $97.2 \%$ of the subjects. All skin irritations after patch removal were mild and were resolved during the study period.

Conclusion: The donepezil patch appeared to be generally well tolerated and adhesive. Pharmacokinetic analysis of the donepezil patch demonstrated linear kinetics.

Keywords: donepezil, transdermal patch, pharmacokinetics, healthy subjects

\section{Introduction}

Alzheimer's disease (AD) is the most common cause of senile dementia. ${ }^{1}$ It was first described by Alois Alzheimer in $1906 .^{2}$ In 2012, there were 36 million people worldwide with AD. It is predicted to affect more than 115 million people globally by $2050 .^{3}$ It is a progressive, neurodegenerative disorder that is usually diagnosed in people over 65 years of age. ${ }^{4}$

Donepezil is a reversible acetylcholinesterase inhibitor that has been approved for use for AD. It is believed to inhibit the breakdown of the neurotransmitter acetylcholine and compensate for the deficiency of acetylcholine in brain. ${ }^{5,6}$ In previous clinical trials, it has been shown to improve cognitive function in patients for a wide range of $\mathrm{AD}$ severity, from very mild to moderate-to-severe..$^{7-11}$

The most common adverse events (AEs) with donepezil, as well as with other cholinesterase inhibitors, are nausea, vomiting, diarrhea, and dizziness, all of which are symptoms linked to cholinergic hyperstimulation. ${ }^{12,13}$ These effects are doserelated and largely depend on the plasma fluctuations. ${ }^{14}$ When donepezil is orally administered, it is well absorbed and reaches peak plasma concentrations $\left(\mathrm{C}_{\max }\right)$ in
Correspondence: Kyun-Seop Bae Department of Clinical Pharmacology and Therapeutics, College of Medicine, University of Ulsan, Asan Medical Center, 88 Olympic-ro 43-gil, Songpa-gu, Seoul 138-736, Republic of Korea

$\mathrm{Tel}+82230104623$

Fax +82 230104622

Email ksbae@amc.seoul.kr 
3-4 hours. ${ }^{15}$ The plasma concentration of donepezil then decreases until the next dose is administered. ${ }^{16}$ By reducing $\mathrm{C}_{\max }$ and slowing the time that it takes to reach $\mathrm{C}_{\max }\left(\mathrm{t}_{\max }\right)$, the potential for these AEs may be attenuated.

The advantages of transdermal drug delivery for AD have already been reported: reduced dosing frequency, improved bioavailability, reduced side effects, and improved patient compliance due to simple application. ${ }^{17-19}$ For this reason, rivastigmine, one of the acetylcholinesterase inhibitors, has already been developed as a transdermal patch. ${ }^{16,20,21}$

The transdermal donepezil patch was also developed for the advantage of providing smooth and steady delivery of donepezil through the skin; a transdermal patch would decrease $\mathrm{C}_{\max }$ and lengthen $\mathrm{t}_{\max }$ while maintaining drug exposure. ${ }^{17}$ According to in vivo studies, when transdermal donepezil (40 mg/kg, $\left.2.14 \mathrm{~cm}^{2}\right)$ was applied to the abdominal skin of male Sprague-Dawley rats, the $\mathrm{C}_{\max }$ at steady state (52.2 ng/mL) was maintained for 48 hours with the donepezil formulation using oleic acid. ${ }^{22}$ The company iCure Pharmaceutical lncorporated (Anseong, Gyeonggi-do, Republic of Korea), which manufactures the donepezil patch that was used in this study, also conducted in vivo studies to evaluate pharmacokinetics. When a single dose of $5 \mathrm{mg} / \mathrm{kg}$ oral solution was administered to Hairless Wistar Yagi rats, the $\mathrm{C}_{\max }$ was $41.4 \mathrm{ng} / \mathrm{mL}$ with a $\mathrm{t}_{\max }$ of 1 hour. When $8.75 \mathrm{mg} / 2.5 \mathrm{~cm}^{2}$, $17.5 \mathrm{mg} / 5 \mathrm{~cm}^{2}$, and $35 \mathrm{mg} / 10 \mathrm{~cm}^{2}$ donepezil patches were applied to Hairless Wistar Yagi rats, the $\mathrm{C}_{\max }$ values were doseproportional $(36.5 \mathrm{ng} / \mathrm{mL}, 64.4 \mathrm{ng} / \mathrm{mL}$, and $129.1 \mathrm{ng} / \mathrm{mL}$, respectively) with $\mathrm{t}_{\max }$ values of $24-36$ hours. ${ }^{23}$

The aim of this randomized, single-blind, placebocontrolled, single-dose, dose-escalation study was to investigate the tolerability and the pharmacokinetics of the novel donepezil patch in healthy male subjects.

\section{Materials and methods Subjects}

Each healthy male volunteer who was $20-45$ years of age and had a body mass index (BMI) of $20-26 \mathrm{~kg} / \mathrm{m}^{2}$ was eligible for this study. Volunteers were considered to be in good health on the basis of these criteria, which were assessed within the 4 weeks prior to the first administration of the study drug: medical history; physical examinations; vital sign measurements (blood pressure, heart rate, and body temperature); 12-lead electrocardiograms (ECGs); clinical laboratory tests (hematology, blood chemistry, and urinalysis); serology (hepatitis B surface antigen, hepatitis $\mathrm{C}$ virus antibody, and HIV antigen/antibody); and urine drug screening (amphetamine, methamphetamine, barbiturate, cocaine, opiate, benzodiazepine, cannabinoid, and methadone). Each subject with a known allergy or hypersensitivity to donepezil or with a history of drug abuse was excluded from the study.

\section{Study design}

The study protocol was approved by the Ministry of Food and Drug Safety (MFDS) and the institutional review board of the Asan Medical Center (AMC), Seoul, Republic of Korea. The study was conducted at the Clinical Trial Center of the AMC from May 2013 to September 2013. All subjects provided written informed consent before screening tests, and this study was conducted in accordance with the Declaration of Helsinki and International Conference of Harmonization (ICH) guidelines for good clinical practice. This trial was registered with the identifier number NCT01860625 at ClinicalTrials.gov.

This study was designed as a randomized, single-blind, placebo controlled, dose-escalation study. In this study, a $3.5 \mathrm{mg} / \mathrm{cm}^{2}$ donepezil patch was applied as a single dose of $43.75 \mathrm{mg} / 12.5 \mathrm{~cm}^{2}, 87.5 \mathrm{mg} / 25 \mathrm{~cm}^{2}$, or $175 \mathrm{mg} / 50 \mathrm{~cm}^{2}$. There were 12 subjects per group, nine of whom were given active patches and three of whom were given placebos. The subjects were admitted to the hospital on the day before drug administration. On the morning of day 1 , each subject received a single application to the upper back with a patch-on period of 72 hours. All subjects were discharged on day 5 ( 24 hours after patch removal), and they revisited the hospital on days $6,7,8,10,12$, and 14 to assess the tolerability and the pharmacokinetics of donepezil. Follow-up visits were performed 18-22 days after the patch application.

For pharmacokinetic analysis, sequential blood samples were collected prior to and at 4, 8, 12, 24, 48, 70, 72, 74, 76, $80,96,120,144,168,216,264$, and 312 hours after patch administration. All blood samples for the determination of donepezil concentrations were drawn into heparinized tubes and separated by centrifugation at $1,800 \times g$ for 8 minutes at $4^{\circ} \mathrm{C}$ and stored at $-70^{\circ} \mathrm{C}$ until analysis.

The adhesive properties of each patch were evaluated every 12 hours (within approximately 30 minutes) from time 0 (the time of adhesion) through 72 hours (before patch removal) after the application of donepezil patch. The adhesiveness of patch was graded according to the criteria in Table $1 .{ }^{24}$

\section{Tolerability}

Tolerability was assessed throughout the study by using vital sign measurements; ECGs; clinical laboratory tests (hematology, blood chemistry, and urinalysis); physical examinations; and monitoring of AEs. AEs were recorded 
Table I Adhesion score and skin irritation score systems in this study

\begin{tabular}{ll}
\hline Adhesion score & Extent of adhesion \\
0 & $\geq 90 \%$ adhesion \\
1 & $\geq 75 \%$ to $<90 \%$ adhesion \\
2 & $\geq 50 \%$ to $<75 \%$ adhesion \\
3 & $<50 \%$ adhesion but patch not detached \\
4 & Patch detached \\
Skin irritation score & Extent of irritation \\
0 & No evidence of irritation \\
1 & Minimal erythema \\
2 & Definite erythema, minimal edema \\
& or minimal papular response \\
3 & Erythema and papules \\
4 & Definite edema \\
5 & Erythema, edema, and papules \\
6 & Vesicular eruption \\
7 & Strong reaction spread beyond test site \\
\hline
\end{tabular}

in terms of symptoms and signs, duration, intensity, relationship to the study drug, action taken, outcome, and seriousness.

Assessment of skin irritation was performed immediately after the removal of the patch ( 72 hours) as well as 1, 12, and 24 hours after patch removal (at 73, 84, and 96 hours after patch application, respectively) by using a skin irritation scoring system (Table 1). ${ }^{24}$ After the subject was discharged, the skin irritation score was assessed at every outpatient visit until that subject experienced an irritation score of 0 .

\section{Determination of donepezil concentrations}

Plasma concentrations of donepezil were determined by using validated high performance liquid chromatography (HPLC) coupled with tandem mass spectrometry. The internal standard was diphenhydramine hydrochloride. The sample extracts were analyzed by using HPLC (Nonospace SI-2 3133; Shiseido, Tokyo, Japan) and an Unison UK-C18 column (3.0 $\mu \mathrm{m}, 50 \mathrm{~mm} * 2.0 \mathrm{~mm}$; Imtakt, Kyoto, Japan) with a mobile phase consisting of ammonium formate with $0.1 \%$ formic acid and acetonitrile with $0.1 \%$ formic acid (40:60, v/v).

The MS system (API-4000" ${ }^{\mathrm{TM}}$; AB Sciex, Framingham, MA, USA) was operated in positive ion electrospray mode with multiple reaction monitoring. For donepezil and the internal standard, the precursor-to-production reactions that were monitored were mass-to-charge ratios $(\mathrm{m} / \mathrm{z})$, $380.3 \rightarrow 91.1$ and $256.2 \rightarrow 167.1$, respectively. All separations were achieved at a flow rate of $0.2 \mathrm{~mL} / \mathrm{min}$.

Calibration curves covered the concentration range of $0.1-80 \mathrm{ng} / \mathrm{mL}\left(R^{2}>0.99\right)$. By using this assay, interday accuracy ranged from $96.27 \%$ to $105.98 \%$, and interday precision, expressed as percent coefficient of variation ( $\% \mathrm{CV})$, ranged from $0.7 \%$ to $4.3 \%$. In addition, intraday accuracy and precision $(\% \mathrm{CV})$ ranged from $97.23 \%$ to $104.92 \%$ and from $1.4 \%$ to $5.3 \%$, respectively.

\section{Pharmacokinetic assessment and statistical analysis}

The plasma concentration-time profiles of donepezil in the subjects were analyzed by using a noncompartmental method and WinNonlin 6.1 (Pharsight Corporation, Princeton, NJ, USA). All analyses were made by using actual times of sampling. The $\mathrm{C}_{\max }$ and $\mathrm{t}_{\max }$ were determined from the observed values. The terminal elimination rate constant $(\lambda z)$ was estimated by linear regression of the terminal loglinear portion of the plasma concentration-time curves. The area under the time-concentration curve (AUC) from time 0 to the last measurable time $\left(\mathrm{AUC}_{\text {last }}\right)$ was calculated by the trapezoidal rule, and the AUC extrapolated to infinity $\left(\mathrm{AUC}_{\text {inf }}\right)$ was obtained as follows:

$$
\mathrm{AUC}_{\text {inf }}=\mathrm{AUC}_{\text {last }}+\mathrm{C}_{\text {last }} / \lambda \mathrm{z}
$$

for which $\mathrm{C}_{\text {last }}$ is the last quantifiable concentration.

The $t_{1 / 2 \beta}$ was calculated for each participant as follows:

$$
\mathrm{t}_{1 / 2 \beta}=\ln (2) / \lambda z
$$

All statistical analyses were performed by using SAS 9.3 (SAS Korea, Seoul, Republic of Korea) and Phoenix WinNonlin 6.1 (Pharsight Corporation). Demographic data and pharmacokinetic parameters were summarized by using descriptive statistics. Dose linearity was investigated by using the Kruskal-Wallis test to evaluate the dose-normalized $\mathrm{C}_{\text {max }}$ and $\mathrm{AUC}_{\text {inf }}$ values.

\section{Results \\ Study participants}

A total of 36 healthy Korean volunteers were enrolled, and 36 subjects were administered the study drugs and completed the study. Expressed as mean \pm standard deviation, the mean characteristics of the study participants were as follows: the mean age was $27.65 \pm 4.54$ years; the mean weight was $67.06 \pm 7.76 \mathrm{~kg}$; and the mean height was $173.79 \pm 4.87 \mathrm{~cm}$.

\section{Pharmacokinetic analysis}

The mean plasma concentration-time profiles of donepezil are shown in Figure 1. After the application of the donepezil 


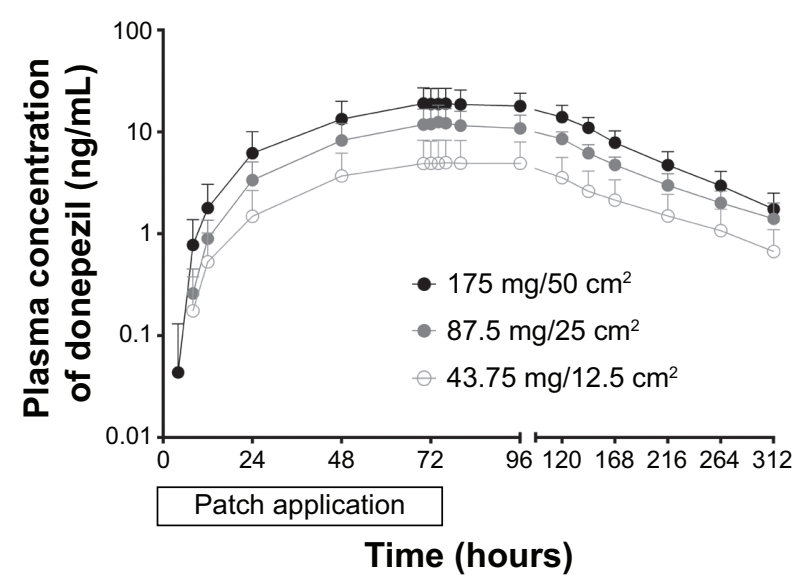

Figure I Plasma concentration-time curves of donepezil 72 hour after patch application.

Notes: Data points are expressed as mean \pm standard deviation. Patch was applied at hour 0 .

patch, serum donepezil concentration increased slowly and peaked between $\sim 74-76$ hours $(\sim 2-4$ hours after patch removal) and declined with a $t_{1 / 2 \beta}$ of $\sim 63.77-94.07$ hours (Table 2). In this study, the dose-normalized $\mathrm{C}_{\max }$ and $\mathrm{AUC}_{\text {inf }}$ values were not statistically significant $(P=0.5986$ and $P=0.3392$, respectively). After patch application, the $\mathrm{C}_{\max }$ and $\mathrm{AUC}_{\text {inf }}$ increased in a dose-proportional manner (Figure 2). Patch adhesiveness was good in $97.2 \%$ of subjects. Only one subject reported that the "patch detached"; this happened more than 61 hours after patch application (Table 3). Used patches from all subjects in each group were analyzed for residual donepezil. The values for average donepezil residue (residual dose/loading dose * 100 [\%]) in the patch 72 hours after application were as follows: $81.1 \% \pm 3.2 \%$ for the $43.75 \mathrm{mg} / 12.5 \mathrm{~cm}^{2}$ group, $80.4 \% \pm 4.4 \%$ for the $87.5 \mathrm{mg} / 25 \mathrm{~cm}^{2}$ group, and $78.4 \% \pm 2.5 \%$ for the $175 \mathrm{mg} / 50 \mathrm{~cm}^{2}$ group.

\section{Tolerability}

Included in the tolerability analysis were 36 subjects, all of whom applied donepezil patch. Eleven subjects experienced a total of 14 AEs, among which ten events in seven subjects were considered "possibly related" to the study drug (Table 4). All AEs were mild except for one case of hypertriglyceridemia in the $43.75 \mathrm{mg} / 12.5 \mathrm{~cm}^{2}$ group. An increase in triglycerides $(1,318 \mathrm{mg} / \mathrm{dL})$ without any symptoms was observed at the follow-up visit, and the decreased level was checked on subsequent visit. Two application-site AEs included skin discoloration and papules; both were resolved without sequelae. No death or serious AEs occurred during the entire course of the study. Likewise, there were no clinically significant abnormalities in vital signs, physical examinations, or electrocardiograms.

The distributions of individual skin irritation scores after patch removal are shown in Figure 3. Immediately after patch removal (72 hours after application), most of the subjects experienced irritation scores of 1 (minimal erythema). All subjects experienced irritation scores of 0 (no evidence of irritation) by the day 12 outpatient visit (approximately 264 hours after patch application). Irritation scores of 4, 5, 6, or 7 were not observed during the entire study.

\section{Discussion}

To our knowledge, this is the first published study to investigate the tolerability and pharmacokinetics of the donepezil patch in healthy subjects. After application, the donepezil patch provided a smooth and sustained plasma concentrationtime profile over the entire patch-on period of 72 hours. For the highest dose of donepezil $\left(175 \mathrm{mg} / 50 \mathrm{~cm}^{2}\right)$ administered in this study, about $20 \%$ of the dose (approximately $35 \mathrm{mg}$ ) was released from the patch over the 72-hour application.

Table 2 Pharmacokinetic parameters of donepezil

\begin{tabular}{|c|c|c|c|}
\hline & \multicolumn{3}{|l|}{ Donepezil dose } \\
\hline & $43.75 \mathrm{mg} / \mathrm{l} 2.5 \mathrm{~cm}^{2}(\mathrm{n}=9)$ & $87.5 \mathrm{mg} / 25 \mathrm{~cm}^{2}(\mathrm{n}=9)$ & $175 \mathrm{mg} / 50 \mathrm{~cm}^{2}(\mathrm{n}=9)$ \\
\hline$A \cup C_{\text {last }}(\mathrm{ng} \cdot \mathrm{h} / \mathrm{mL})$ & $716.82 \pm 427.94$ & $\mathrm{I}, 600.24 \pm 408.48$ & $2,574.32 \pm 899.07$ \\
\hline $\mathrm{AUC}_{\text {inf }}(\mathrm{ng} \cdot \mathrm{h} / \mathrm{mL})$ & $808.52 \pm 474.05$ & $1,762.42 \pm 431.95$ & $2,761 .|5 \pm 889.7|$ \\
\hline $\mathrm{AUC}_{\mathrm{in}} /$ dose $(\mathrm{ng} \cdot \mathrm{h} / \mathrm{mL} / \mathrm{mg})$ & $18.48 \pm 10.84$ & $20.14 \pm 4.94$ & $15.78 \pm 5.08$ \\
\hline $\mathrm{C}_{\max }(\mathrm{ng} / \mathrm{mL})$ & $5.24 \pm 3.43$ & $13.00 \pm 5.45$ & $20.36 \pm 7.43$ \\
\hline $\mathrm{C}_{\max } /$ dose $(\mathrm{ng} / \mathrm{mL} / \mathrm{mg})$ & $0.12 \pm 0.08$ & $0.15 \pm 0.06$ & $0.12 \pm 0.04$ \\
\hline $\mathrm{t}_{1 / 2 \beta}$ (hours) & $94.07 \pm \mid 9.61$ & $75.52 \pm 15.44$ & $63.77 \pm 11.27$ \\
\hline $\mathrm{CL} / \mathrm{F}(\mathrm{L} / \mathrm{h})$ & $72.28 \pm 38.00$ & $52.31 \pm 12.47$ & $70.49 \pm 25.73$ \\
\hline $\mathrm{t}_{\max }$ (hours) & $76.0(70.0,95.9)$ & $76.0(74.0,119.2)$ & $74.0(70.0,119.2)$ \\
\hline
\end{tabular}

Notes: Data are presented as mean \pm standard deviation, except for $t_{\text {max }}$, which is expressed as median (minimum, maximum).

Abbreviations: $n$, number of subjects; $A \cup C_{\text {last }}$, area under the plasma concentration-time curve from time 0 to last measurable time point; $A U C_{\text {inf }}$ area under the plasma concentration-time curve from time 0 to infinity; $C_{\max }$, measured peak plasma concentration; $t_{1 / 2 \beta}$, terminal half-life; $C L / F$, oral clearance; $t_{\text {max }}$, time to reach peak concentration. 
A

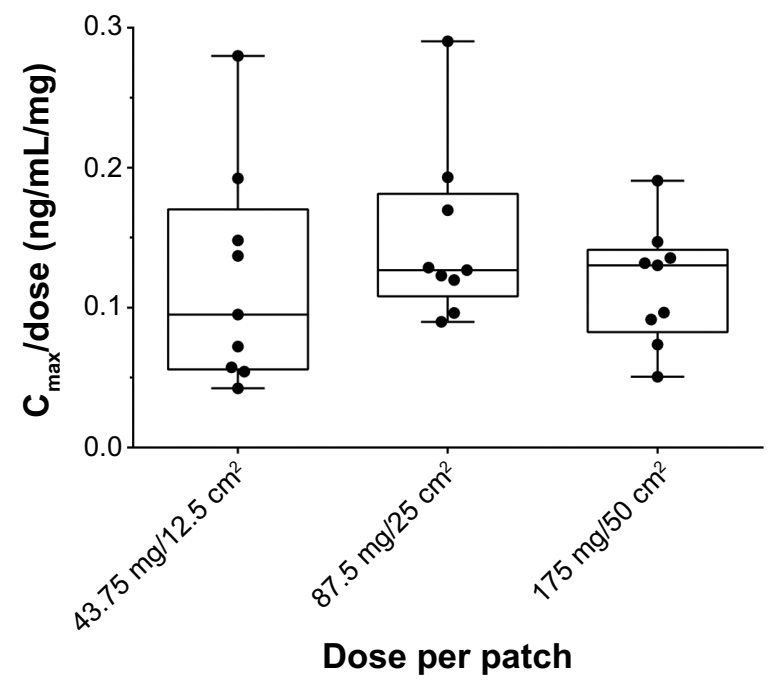

B

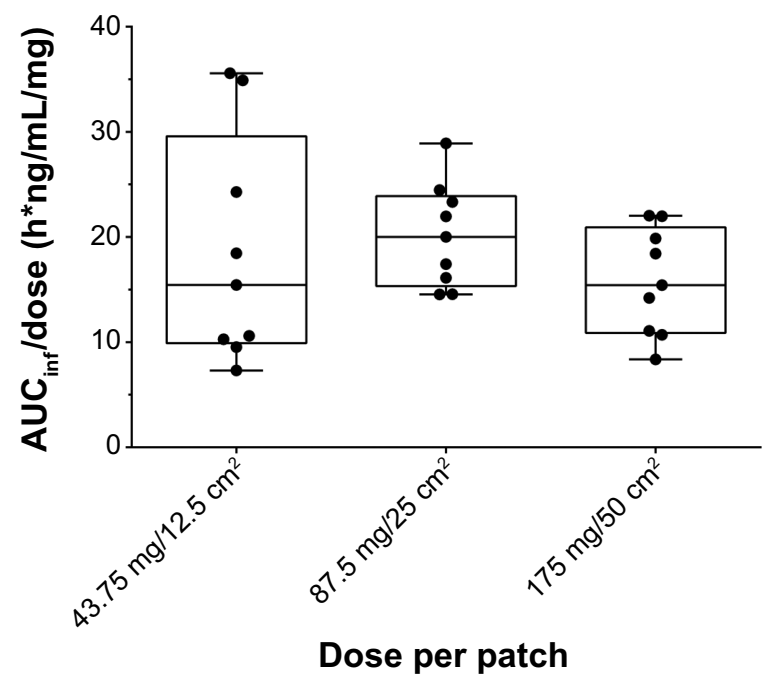

Figure 2 Box-Whisker plots of donepezil pharmacokinetics in subjects 72 hours after patch application.

Notes: Box-Whisker plots of $C_{\text {/ }}$ /dose for donepezil (A) and of AUC /dose for donepezil (B) 72 hours after application of the donepezil patch. The box edges indicate the minimum and the maximum values of each parameter. The whiskers extend from the 25 th and 75 th quartiles, and the line in the middle indicates the median value.

Abbreviations: $\mathrm{AUC}_{\text {in }}$, area under the plasma concentration-time curve from time 0 to infinity; $\mathrm{AUC}_{\text {in }} /$ dose, dose-normalized area under the plasma concentration-time curve from time 0 to infinity; $C_{\max }$, measured maximum plasma concentration; $C_{\max } /$ dose, dose-normalized measured maximum plasma concentration.

As per the clinical pharmacology and biopharmaceutics review, the pharmacokinetic profile of $10 \mathrm{mg}$ single-dose oral donepezil was reported to produce an $\mathrm{AUC}_{\text {inf }}$ of $885.30 \pm 249.10 \mathrm{ng} / \mathrm{mL}$ and $\mathrm{a}_{\max }$ of $20.90 \pm 5.00 \mathrm{ng} / \mathrm{mL} .{ }^{25}$ Systemic exposure $\left(\mathrm{AUC}_{\text {inf }}\right)$ after a 72-hour application of $175 \mathrm{mg} / 50 \mathrm{~cm}^{2}$ was about three times higher than after the single dose of a $10 \mathrm{mg}$ oral tablet, while the $\mathrm{C}_{\max }$ with the patch was similar to the $\mathrm{C}_{\max }$ with a $10 \mathrm{mg}$ dose of oral donepezil. Thus, this transdermal dose (about $35 \mathrm{mg} / 72$ hours) is expected to produce exposure (AUC) similar to 3 days of $10 \mathrm{mg}$ oral donepezil but with a lower $\mathrm{C}_{\max }$.

In the $43.75 \mathrm{mg} / 12.5 \mathrm{~cm}^{2}$ group, the $\% \mathrm{CV}$ of $\mathrm{AUC}_{\text {inf }}$ was larger than in the other treatment groups $(58.6 \%$ in the 43.75 $\mathrm{mg} / 12.5 \mathrm{~cm}^{2}$ group, $24.5 \%$ in the $87.5 \mathrm{mg} / 25 \mathrm{~cm}^{2}$ group, and $32.2 \%$ in the $175 \mathrm{mg} / 50 \mathrm{~cm}^{2}$ group). Of the nine subjects in the group, two showed lower clearances (28.1 and 28.7 L/hour) than average (72.3 L/hour), so the $\mathrm{AUC}_{\text {inf }}$ of each of these subjects was higher $(1556.5 \mathrm{ng} \cdot \mathrm{h} / \mathrm{mL}$ and $1526.8 \mathrm{ng} \cdot \mathrm{h} / \mathrm{mL}$, respectively) than average $\mathrm{AUC}_{\mathrm{inf}}(808.5 \mathrm{ng} \cdot \mathrm{h} / \mathrm{mL})$. Although we did not evaluate the different genotypes, the difference between CYP2D6 could have been one of the reasons for the large interindividual variability. In a recent population pharmacokinetic study in which donepezil clearance was evaluated in CYP2D6 genotypes, CYP2D6-poor metabolizers demonstrated a 32\% lower clearance than did CYP2D6extensive metabolizers. ${ }^{26}$

The disadvantages of transdermal delivery include skin irritation and imperfect adhesion to the skin. ${ }^{19}$ In this study, the results for skin irritation indicate that the skin reactions to the study drug were mild. The highest score was 3 (erythema and papules); this was seen in two subjects, and the condition was resolved to 0 (no evidence of irritation)

Table 3 Patch adhesion scores during 72-hour donepezil patch administration

\begin{tabular}{|c|c|c|c|}
\hline \multirow{2}{*}{$\begin{array}{l}\text { Hours after patch } \\
\text { administration }\end{array}$} & \multicolumn{3}{|l|}{ Donepezil dose } \\
\hline & $43.75 \mathrm{mg} / \mathrm{l} 2.5 \mathrm{~cm}^{2}(\mathrm{n}=9)$ & $87.5 \mathrm{mg} / 25 \mathrm{~cm}^{2}(\mathrm{n}=9)$ & $175 \mathrm{mg} / 50 \mathrm{~cm}^{2}(\mathrm{n}=9)$ \\
\hline 0 & $0(0,0)$ & $0(0,0)$ & $0(0,0)$ \\
\hline 12 & $0(0,0)$ & $0(0,0)$ & $0(0,0)$ \\
\hline 24 & $0(0,0)$ & $0(0,0)$ & $0(0,1)$ \\
\hline 36 & $0(0,0)$ & $0(0,1)$ & $0(0,1)$ \\
\hline 48 & $0(0,1)$ & $0(0,1)$ & $0(0,1)$ \\
\hline 60 & $0(0,1)$ & $0(0,2)$ & $0(0,1)$ \\
\hline 72 & $0(0,1)$ & $0(0,4)$ & $0(0,2)$ \\
\hline
\end{tabular}

Notes: Data are presented as median (minimum, maximum). Under "Hours after patch administration", the value 0 indicates the point at which the patch was attached. Abbreviation: $\mathrm{n}$, number of subjects. 
Table 4 Summary of AEs and causal relationship after donepezil patch administration

\begin{tabular}{|c|c|c|c|c|c|c|c|}
\hline \multirow[t]{3}{*}{ Type of AE } & \multirow{3}{*}{$\begin{array}{l}\begin{array}{l}\text { Placebo } \\
(n=9)\end{array} \\
\text { All AEs }\end{array}$} & \multicolumn{6}{|c|}{ Donepezil patch dose } \\
\hline & & \multicolumn{2}{|c|}{$43.75 \mathrm{mg} / \mathrm{l} 2.5 \mathrm{~cm}^{2}(\mathrm{n}=9)$} & \multicolumn{2}{|c|}{$87.5 \mathrm{mg} / 25 \mathrm{~cm}^{2}(\mathrm{n}=9)$} & \multicolumn{2}{|c|}{$175 \mathrm{mg} / 50 \mathrm{~cm}^{2}(\mathrm{n}=9)$} \\
\hline & & All AEs & Drug-related AEs & All AEs & Drug-related AEs & All AEs & Drug-related AEs \\
\hline Total & $2(3)$ & $3(3)$ & $I(I)$ & $2(2)$ & $2(2)$ & $4(6)$ & $3(5)$ \\
\hline Hypertriglyceridemia & $I(I)$ & $I(I)$ & $0(0)$ & $0(0)$ & $0(0)$ & $0(0)$ & $0(0)$ \\
\hline Nasal stuffiness & $I(I)$ & $0(0)$ & $0(0)$ & $0(0)$ & $0(0)$ & $0(0)$ & $0(0)$ \\
\hline Rhinorrhea & $I(I)$ & $0(0)$ & $0(0)$ & $0(0)$ & $0(0)$ & $0(0)$ & $0(0)$ \\
\hline Diarrhea & $0(0)$ & $\mathrm{I}(\mathrm{I})$ & $0(0)$ & $0(0)$ & $0(0)$ & $0(0)$ & $0(0)$ \\
\hline Papules on patch adhesion site & $0(0)$ & $I(I)$ & $I(I)$ & $0(0)$ & $0(0)$ & $0(0)$ & $0(0)$ \\
\hline Skin discoloration, patch adhesion site & $0(0)$ & $0(0)$ & $0(0)$ & $I(I)$ & $\mathrm{I}(\mathrm{I})$ & $0(0)$ & $0(0)$ \\
\hline Bilirubin total increased & $0(0)$ & $0(0)$ & $0(0)$ & $I(I)$ & $\mathrm{I}(\mathrm{I})$ & $0(0)$ & $0(0)$ \\
\hline Ankle sprain & $0(0)$ & $0(0)$ & $0(0)$ & $0(0)$ & $0(0)$ & $I(I)$ & $0(0)$ \\
\hline Headache & $0(0)$ & $0(0)$ & $0(0)$ & $0(0)$ & $0(0)$ & $\mathrm{I}(\mathrm{I})$ & $\mathrm{I}(\mathrm{I})$ \\
\hline Abdominal discomfort & $0(0)$ & $0(0)$ & $0(0)$ & $0(0)$ & $0(0)$ & $I(I)$ & $I(I)$ \\
\hline Upper abdominal discomfort & $0(0)$ & $0(0)$ & $0(0)$ & $0(0)$ & $0(0)$ & $I(I)$ & $\mathrm{I}(\mathrm{I})$ \\
\hline Nausea & $0(0)$ & $0(0)$ & $0(0)$ & $0(0)$ & $0(0)$ & I (I) & I (I) \\
\hline Vomiting & $0(0)$ & $0(0)$ & $0(0)$ & $0(0)$ & $0(0)$ & I (I) & I (I) \\
\hline
\end{tabular}

Note: Data are presented as $n$ (number of events).

Abbreviations: $A E$, adverse event; $n$, number of subjects.

A

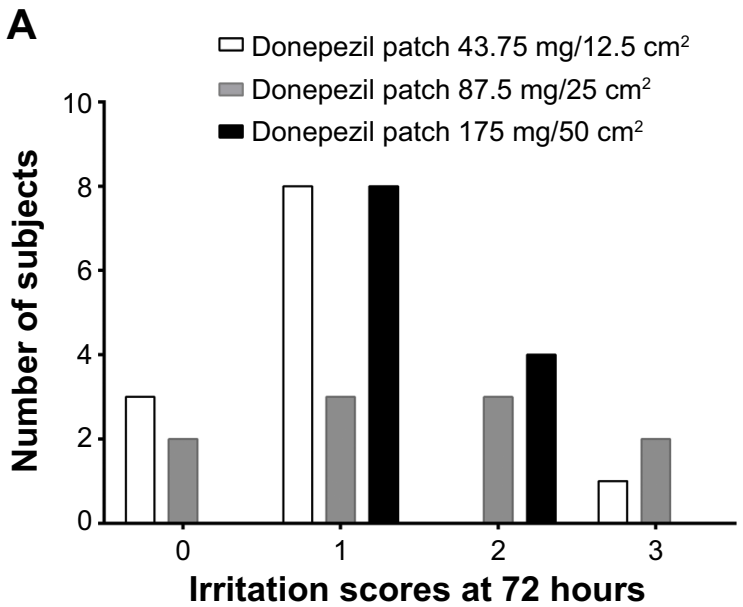

C

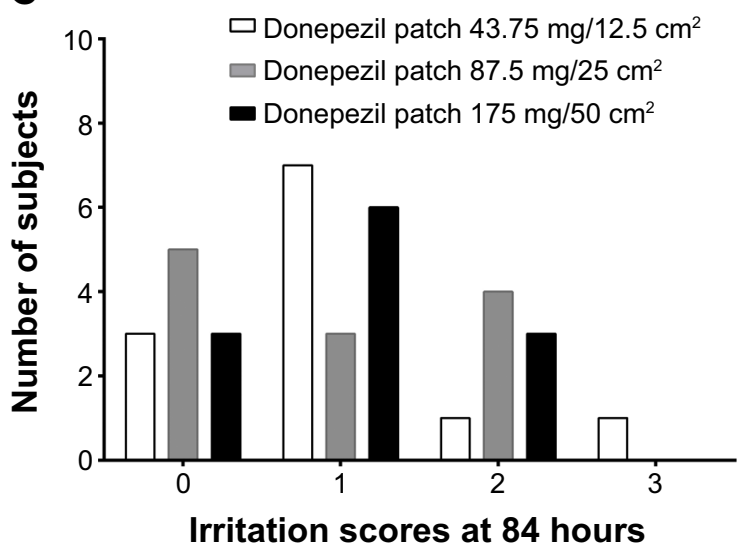

B

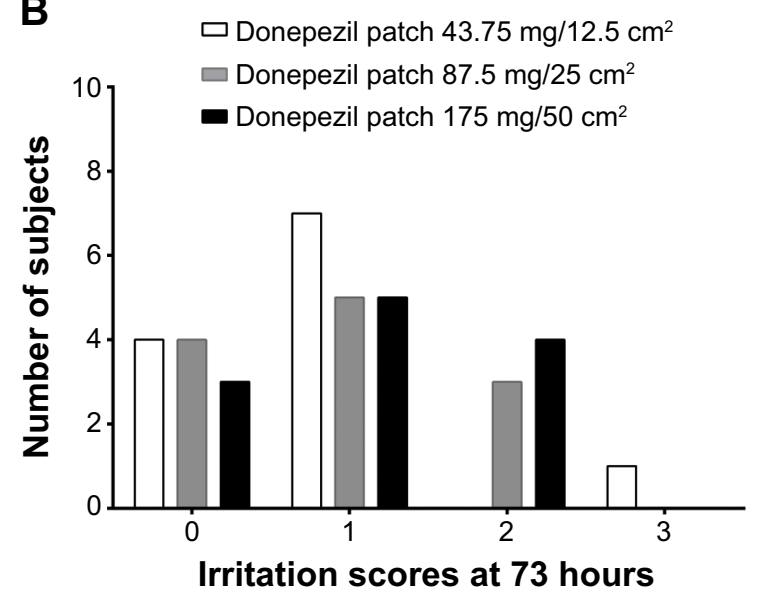

D

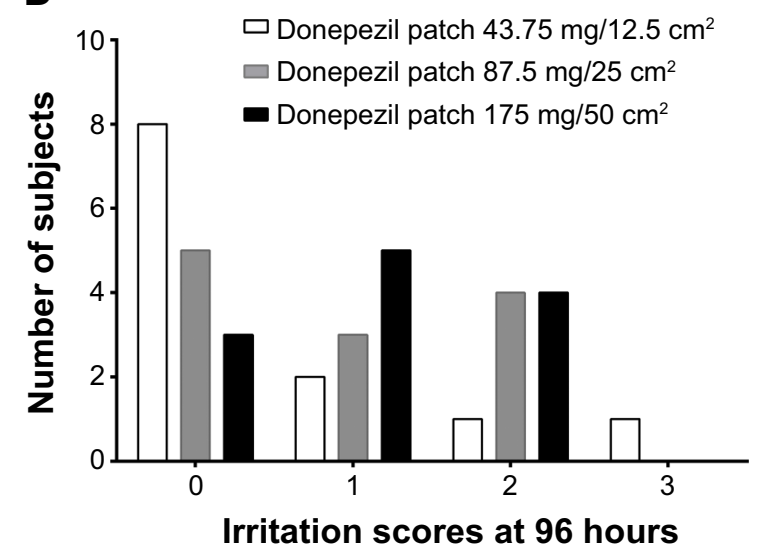

Figure 3 Distribution of individual skin irritation scores after removal of the donepezil patch.

Notes: Data are for irritation scores assessed at these times: the time of patch removal, which was 72 hours after patch application (A); I hour after patch removal, which was 73 hours after patch application (B) 12 hours after patch removal, which was 84 hours after patch application (C); 24 hours after patch removal, which was 96 hours after patch application (D). The scores are defined as follows: 0 , no evidence of irritation; I, minimal erythema; 2 , definite erythema, readily visible; 3 , erythema and papules. 
within 8 days. The adhesiveness of the donepezil patch was also good. Except for one subject, the individual adhesion scores ranged between 0 ( $\geq 90 \%$ adherence) and 2 (adherence of $\geq 50 \%$ to $<75 \%$ ) for 72 hours.

Our study had limitations that should be considered. First, these results were obtained from healthy male subjects; the tolerability and pharmacokinetics of donepezil patch may differ in female or elderly AD patients. Second, donepezil accumulated in plasma by four to seven-fold until the steady state; further evaluation and comparison of the steady-state pharmacokinetics of the donepezil patch is needed. ${ }^{27}$ On the basis of the findings of this study, the investigation of multiple doses in healthy volunteers or elderly AD patients may be helpful to evaluate steady-state pharmacokinetics and to prove the optimal way to treat $\mathrm{AD}$ with donepezil.

\section{Conclusion}

This study represents the first assessment of a single-dose donepezil patch in human subjects. Overall, the donepezil patch appeared to be generally well tolerated and adhesive. The pharmacokinetic characteristics of the donepezil patch demonstrated linear kinetics.

\section{Acknowledgments}

This study was conducted by the AMC and was supported by a grant from the Korean Health Technology R\&D Project, Ministry of Health and Welfare, Republic of Korea (HI14C1061). This study was also supported by a grant from the Korea Health Technology R\&D Project through the Korea Health Industry Development Institute, funded by the Ministry of Health and Welfare, Republic of Korea (HI12C1449).

\section{Disclosure}

All of the authors report that they have no conflicts of interest in this work. The study was funded by iCure Pharmaceutical Inc., the manufacturer of the donepezil patch that was used in this study. The sponsor's financial support did not include bonuses for the success of the present study or for the recruitment of subjects.

\section{References}

1. Small GW, Rabins PV, Barry PP, et al. Diagnosis and treatment of Alzheimer disease and related disorders. Consensus statement of the American Association for Geriatric Psychiatry, the Alzheimer's Association, and the American Geriatrics Society. JAMA. 1997;278(16): 1363-1371.

2. Berchtold NC, Cotman CW. Evolution in the conceptualization of dementia and Alzheimer's disease: Greco-Roman period to the 1960s. Neurobiol Aging. 1998;19(3):173-189.
3. Alzheimer's Disease International. World Alzheimer Report 2012 Overcoming the Stigma of Dementia. London: Alzheimer's Disease International; 2012. Available from: http://www.alz.co.uk/research/ WorldAlzheimerReport2012.pdf. Accessed November 11, 2014.

4. Brookmeyer R, Gray S, Kawas C. Projections of Alzheimer's disease in the United States and the public health impact of delaying disease onset. Am J Public Health. 1998;88(9):1337-1342.

5. Francis PT, Palmer AM, Snape M, Wilcock GK. The cholinergic hypothesis of Alzheimer's disease: a review of progress. $J$ Neurol Neurosurg Psychiatry. 1999;66(2):137-147.

6. Giacobini E. Pharmacotherapy of Alzheimer disease: new drugs and novel strategies. Prog Brain Res. 1993;98:447-454.

7. Rogers SL, Friedhoff LT. The efficacy and safety of donepezil in patients with Alzheimer's disease: results of a US Multicentre, Randomized, Double-Blind, Placebo-Controlled Trial. The Donepezil Study Group. Dementia. 1996;7(6):293-303.

8. Seltzer B, Zolnouni P, Nunez M, et al; Donepezil “402" Study Group. Efficacy of donepezil in early-stage Alzheimer disease: a randomized placebo-controlled trial. Arch Neurol. 2004;61(12): $1852-1856$.

9. Winblad B, Kilander L, Eriksson S, et al. Donepezil in patients with severe Alzheimer's disease: double-blind, parallel-group, placebocontrolled study. Lancet. 2006;367(9516):1057-1065.

10. Rogers SL, Doody RS, Mohs RC, Friedhoff LT. Donepezil improves cognition and global function in Alzheimer disease: a 15-week, doubleblind, placebo-controlled study. Donepezil Study Group. Arch Intern Med. 1998;158(9):1021-1031.

11. Tsuno N. Donepezil in the treatment of patients with Alzheimer's disease. Expert Rev Neurother. 2009;9(5):591-598.

12. Rogers SL, Farlow MR, Doody RS, Mohs R, Friedhoff LT. A 24-week, double-blind, placebo-controlled trial of donepezil in patients with Alzheimer's disease. Donepezil Study Group. Neurology. 1998; 50(1):136-145.

13. Burns A, Rossor M, Hecker J, et al. The effects of donepezil in Alzheimer's disease - results from a multinational trial. Dement Geriatr Cogn Disord. 1999;10(3):237-244.

14. Imbimbo BP. Pharmacodynamic-tolerability relationships of cholinesterase inhibitors for Alzheimer's disease. CNS Drugs. 2001;15(5): 375-390.

15. Jann MW, Shirley KL, Small GW. Clinical pharmacokinetics and pharmacodynamics of cholinesterase inhibitors. Clin Pharmacokinet. 2002;41(10):719-739.

16. Kurz A, Farlow M, Lefévre G. Pharmacokinetics of a novel transdermal rivastigmine patch for the treatment of Alzheimer's disease: a review. Int J Clin Pract. 2009;63(5):799-805.

17. Sozio P, Cerasa LS, Marinelli L, Di Stefano A. Transdermal donepezil on the treatment of Alzheimer's disease. Neuropsychiatr Dis Treat. 2012; 8:361-368.

18. Priano L, Gasco MR, Mauro A. Transdermal treatment options for neurological disorders: impact on the elderly. Drugs Aging. 2006; 23(5):357-375.

19. Chan AL, Chien YW, Jin Lin S. Transdermal delivery of treatment for Alzheimer's disease: development, clinical performance and future prospects. Drugs Aging. 2008;25(9):761-775.

20. Mercier F, Lefévre G, Huang HL, Schmidli H, Amzal B, AppelDingemanse $\mathrm{S}$. Rivastigmine exposure provided by a transdermal patch versus capsules. Curr Med Res Opin. 2007;23(12):3199-3204.

21. Winblad B, Cummings J, Andreasen N, et al. A six-month doubleblind, randomized, placebo-controlled study of a transdermal patch in Alzheimer's disease - rivastigmine patch versus capsule. Int J Geriatr Psychiatry. 2007;22(5):456-467.

22. Choi J, Choi MK, Chong S, Chung SJ, Shim CK, Kim DD. Effect of fatty acids on the transdermal delivery of donepezil: in vitro and in vivo evaluation. Int J Pharm. 2012;422(1-2):83-90. 
23. iCure. (donepezil patch) [Investigator's brochure]. iCure Pharmaceutical; version 02. Release Date: March 24, 2014.

24. US Food and Drug Administration, Center for Drug Evaluation and Research. Guidance for Industry: Skin Irritation and Sensitization Testing of Generic Transdermal Drug Products. Silver Spring: US Food and Drug Administration; 1999. Available from: http://www.fda.gov/ ohrms/dockets/98fr/990236Gd.pdf. Accessed November 18, 2014.

25. US Food and Drug Administration, Center for Drug Evaluation and Research. Application Number 022568. Clinical pharmacology and biopharmaceutics review(s). Silver Spring: US Food and Drug Administration; 2009. Available from: http://www.accessdata.fda.gov/ drugsatfda_docs/nda/2010/022568orig1s000clinpharmr.pdf. Accessed November 20, 2014.
26. Noetzli M, Guidi M, Ebbing K, et al. Population pharmacokinetic approach to evaluate the effect of CYP2D6, CYP3A, ABCB1, POR and NR1I2 genotypes on donepezil clearance. $\mathrm{Br} J$ Clin Pharmacol. 2014;78(1):135-144.

27. Seltzer B. Donepezil: a review. Expert Opin Drug Metab Toxicol. 2005; 1(3):527-536

\section{Publish your work in this journal}

Drug Design, Development and Therapy is an international, peerreviewed open-access journal that spans the spectrum of drug design and development through to clinical applications. Clinical outcomes, patient safety, and programs for the development and effective, safe, and sustained use of medicines are a feature of the journal, which has also been accepted for indexing on PubMed Central. The manuscript management system is completely online and includes a very quick and fair peer-review system, which is all easy to use. Visit http://www.dovepress.com/testimonials.php to read real quotes from published authors.

Submit your manuscript here: http://www.dovepress.com/drug-design-development-and-therapy-journal 